\title{
Characteristics of erosion and deposition of straw checkerboard barriers in alpine sandy land
}

\author{
Tian Lihui - Wu Wangyang - Zhang Dengshan • \\ Lu Ruijie • Wang Xuequan
}

Received: 25 February 2014/ Accepted: 12 January 2015/Published online: 3 February 2015

(C) Springer-Verlag Berlin Heidelberg 2015

\begin{abstract}
The morphology and stability of concave surface of the straw checkerboard barriers are the fundamental guiding principles of exploring the mechanism of erosion and deposition, evaluating effectiveness and life period, and optimizing the physical structures of the sand barriers. Especially, in alpine sandy land, characteristics of erosion (deposition) and capacity for anti-erosion and sand burial of straw checkerboard barriers are significantly different from the arid and semi-arid desert regions. Erosion (deposition) measurements and wind-sand observations for different specifications $(1 \mathrm{~m} \times 1 \mathrm{~m}, 1.5 \mathrm{~m} \times 1.5 \mathrm{~m}$ and $2 \mathrm{~m} \times 2 \mathrm{~m}$ ) and slope positions (toe, middle and top of the windward areas) of wheat straw checkerboard barriers were adopted in the eastern shore of the Qinghai Lake study area. The different sizes of straw checkerboards at different windward areas have distinctly erosive and depositional stability and intensity. Including the checkerboards with $1.5 \mathrm{~m} \times 1.5 \mathrm{~m}$ (medium) size at the middle and top, $1 \mathrm{~m} \times 1 \mathrm{~m}$ (small) size at the top and $2 \mathrm{~m} \times 2 \mathrm{~m}$ (large) size at the toe, all the erosion (deposition) coefficients are between 0.09 and 0.11 , while their intensities of accumulation are relatively steady $\left(70-90 \mathrm{~kg} \mathrm{~m}^{-2}\right)$, which are the easiest to form stable concaves, and the heights of the
\end{abstract}

T. Lihui · W. Wangyang $(\varangle) \cdot$ Z. Dengshan $\cdot$ L. Ruijie Key Laboratory of Environmental Changes and Natural Disaster, Ministry of Education, Beijing Normal University,

Beijing 100875, China

e-mail: bnuwwy@yeah.net

Z. Dengshan

Qinghai Academy of Agricultural Forestry Sciences,

Xining 810016, China

W. Xuequan

Institute of Desertification Studies, Chinese Academy of

Forestry, Beijing, China barriers change least. Nevertheless, the concaves with small size at the toe are seriously buried, but eroded in the center of some checkerboards with large size at the top, which lead to a short protective period within 3 years and an unbalance between erosion and deposition. Moreover, the transects of erosion (deposition) dominated by southwesterly and northwesterly winds reflect the different intensities of erosion (deposition) at various orientations. On the transect of the NW-SE orientation, at the dune section, each square in the NW direction is strongly accumulated, and the center-SE azimuth is weakly eroded. Usually, deeper accumulation in the center of transects happen in those checkerboards with smaller size and lower terrain slope, which is mainly caused by an obviously positive correlation between the northwest and southwest wind velocity and the erosive depth, and the same is true with the wind frequency (all correlation coefficients are between 0.85 and 0.95 ). Taking the characteristics of erosion (deposition), sand protection benefits and costs of all types into account, large size at the toe and medium size at the middle of windward slope are the most practical combinations, while small size is suitable to play an emergency treatment role in some extremely serious hazard areas in alpine sandy land.

Keywords Alpine sandy land - Straw checkerboard of wheat · Fitting curve $\cdot$ Erosion (deposition) coefficient $\cdot$ Intensity of erosion (deposition)

\section{Introduction}

The wheat straw checkerboard barrier is an innovative feature in China's long history of anti-desertification. It has been extensively studied and demonstrated to be a simple, 
feasible, and effective mechanical sand control measure (Wu 2009). Straw sand barriers increase the surface roughness through outcropping, reducing the air velocity near the resistant ground to achieve the effect of sand fixation, meanwhile, gradually improving the soil moisture and promoting natural revegetation (Chepil and Woodruff 1963). Straw checkerboard barriers have been widely used because they comprise simple economic materials, have minimal difficulty of technical construction, and do not have any ecological side effects (Ci 1998). During the 1950s and 1960s, when the Baotou-Lanzhou railway was constructed, straw checkerboard barriers were promoted in expansive trials. In subsequent decades of experimental research, areas measuring $1 \mathrm{~m} \times 1 \mathrm{~m}$ in size were determined to have excellent suitability. Afterwards, in the arid and semi-arid desert region in northern China, the size, height, material porosity, protective width and other structural indicators of straw checkerboard barriers were verified using theoretical improvements in various areas. Liu et al. (1983) established the barrier spacing and the maximum erosion depth from analytical relationships based on wind tunnel tests of a mathematical derivation and the angle of repose of dry sand. Sun and Guo (1999) used a sand barrier to control the sand-flow erosion and deposition mechanisms to build a sand barrier control erosion formula determined by the barrier height and spacing. Based on the characteristics of fluctuating wind velocity, Zhang et al. (2006) observed that in straw checkerboard barriers, an inverse relationship exists between the porosity and vortex erosion behind checkerboard barriers. According to the factors of the manner and speed of sand burials, as well as local wind conditions, $\mathrm{Xu}$ et al. (1982) estimated the protective life of straw checkerboard barriers to establish a linear relationship between the width of sand barriers and their effective years of use. In the Tengger Desert, Kubuqi Desert, Kumtag Desert, Xinjiang basins and other arid and semi-arid desert areas, the sand-fixation efficiency of straw checkerboard barriers, the soil improvement benefits and revegetation have been completely confirmed (Dong et al. 2006; Li et al. 2006; Li 1999; Fang et al. 2007). However, the macro-effectiveness of different sizes of checkerboards should be based on the erosion and deposition mechanism inside the square, its size configuration based on the fitting curve's erosion (deposition) morphology and the intensity of erosion (deposition). Nevertheless, there is little research examining the effectiveness of erosion (deposition) inside the checkerboard, and a small number of studies focus on the simulation analysis on the cell flow field in wind tunnel tests (Bofah and Alhinai 1986; Qiu et al. 2004; Huang et al. 2013). Thus, enhancing the analysis of a fitting curve's erosion (deposition) features may serve to illustrate the method of protection, thereby extending the service life and achieving the best protective effect of straw checkerboard barriers (Iversen and Rasmussen 1999; Dong et al. 2007).

Currently, many scholars generally believe that a stable fitting curve is important to the erosion and deposition mechanism in straw checkerboard barriers, which have a normal arrangement, faced with a lift effect of unsaturated sand flow and the formation of non-accumulated handling conditions. In this process, the erosion (deposition) coefficient of $1 / 8$ to $1 / 10$ (or $1 / 10$ to $1 / 12$ ) becomes the core evaluation indicator to the stable fitting curve in the checkerboard (Qu et al. 2005; Wang and Zhao 2002). Domestic scholars have studied the fitting curve morphology of checkerboard barriers, including their materials, structure and monitoring methods. Chang et al. (2000) defined the stable fitting curve as the erosion amount's being equal to the amount of accumulated sediment according to the principles of wind erosion, and this researcher established a function of the barrier distance and the slope through a multiple regression with a slope between $0^{\circ}$ and $10^{\circ}$ and the spacing of straw checkerboard laid between approximately 1.5 and $2 \mathrm{~m}$. Based on the view of fluid mechanics, Wang and Zheng (2002) established a height correspondence and maximum spacing of which an area $1 \mathrm{~m} \times 1 \mathrm{~m}$ should match an approximately $15-20-\mathrm{cm}-$ high barrier. Ding et al. (2009) used a three-dimensional laser scanner to monitor changes in erosion and deposition in a straw grid, resulting in the micro-morphology and three-dimensional display of the fitting curve. In addition, Han et al. (2000) and Zhou et al. (2009) studied the erosion and deposition characteristics of a sandbag sand barrier fitting curve, combining a wind tunnel simulation with experiments on field measurements and concluding that a $1 \mathrm{~m} \times 1 \mathrm{~m}$ grid sandbag was the most conducive to the formation of a stable fitting curve. Ma et al. (2005) and Sun et al. (2012) stated that there is a difference between the erosion and deposition conditions of straw checkerboard and clay barriers. These researchers' results show that the plastic checkerboard barrier is more suitable for the restoration and reconstruction of degraded vegetation in arid regions. Wang et al. (2009) derived the clay sand barrier applicability in the Gonghe Basin from the benefits of sand fixation and yearly protection. Overall, the micro-morphological erosion (deposition) of the fitting curve in the checkerboard barriers has been minimally studied, with the only virtue being the erosion (deposition) coefficient as a single evaluation index that is not stable or widely adaptable. A combination of erosion (deposition) intensity, erosion (deposition) rates and other indicators of local conditions are required to evaluate the stability, size and other indicators of suitability. In the study of a checkerboard barrier's structural configuration that mainly focused on the size and height of barriers, the porosity and design 
materials, an indoor wind tunnel or numerical simulation were the primary methods. Research on the terrain slope was primarily performed on sand dunes without barrier measures (Daniel et al. 2004, Han et al. 2000; Fluent 1998; Li 2010) and focused less on the rational allocation of straw checkerboard barriers in different slope sites. Especially given the overreliance on field experiences laying straw checkerboard barriers, it is necessary to evaluate comprehensively the micro-morphological analysis and quantification of erosion (deposition) characteristics and sizes which need to be selected.

In contrast with the earlier anti-desertification work and the significant treatment effect in arid and semi-arid desert regions in northern China, the desertification prevention and control of alpine sandy lands did not begin until the 1960s (Dong et al. 1993; Dong and Liu 1993; Li and Lei 2003; Qian 1986; Zhang and Gao 2007), taking place primarily in the Gonghe Basin, Qaidam Basin, Qinghai Lake drainage, Three Rivers in Tibet, as well as several Tibetan highways and along the Qinghai-Tibet Railway. The means of prevention and treatment included the mechanical engineering of a high vertical barrier of sand fences, wheat straw, and gravel checkerboard barriers (An et al. 2011; Niu 1999; Yang et al. 1997; Wang and Shen 2001)

However, because of the unique alpine climate, the valley topography of salt lakes or rivers and the sensitive fragile alpine ecosystems (Zhang et al. 2011a, b), the numerous sand control measures were significantly different from the arid and semi-arid desert region. Clay, reeds and other environmentally friendly materials are scarce, and plastic, nylon nets and other chemical materials have a high economic cost and side effects on ecological restoration. Furthermore, gravel is not feasible in sandy land. In places where barley and wheat are planted, the straw checkerboard barrier is most widely adaptable. Compared to the arid and semi-arid desert region, the impacts on the lake and river valley are different, the average annual precipitation is greater and the wind direction is complex in the alpine sandy land (Chen et al. 1964). Additionally, the particle size is larger, the topsoil is better sorted, and the erosion rate is also more accurate than other sandy land in northern China (Liu et al. 2006; Liu 1999). The wheat straw checkerboard barrier has a shorter protective life, but the effect is more obvious in terms of the short-term windbreak and sand fixation, and the primary function is to protect the fast-fixed artificial sand and vegetation growth (Zhang 2009). Although the $1 \mathrm{~m} \times 1 \mathrm{~m}$ standard configuration is different from the other sandy areas, according to other studies, the $1 \mathrm{~m}$ spacing of sand is extremely serious in sand burial and severe erosion in the center of $2 \mathrm{~m}$ spacing results in less straw checkered life than in the windy season (He et al. 1993). Thus, considering the different parts of the dune erosion and deposition conditions, the selected sizes are targeted. In the Gonghe Basin and Qinghai Lake Basin sandy areas, the straw checkerboard barriers were of various types but remained in the experimental and engineering testing stage, and the barriers' maximum benefit of protection were not determined through experiments under various terrain conditions examining the erosion and deposition morphology and effects monitoring.

Considering the importance of micro-morphological erosion (deposition) and lack of research investigating for alpine sandy lands, this paper chose the Ketu sandy land along the eastern shore of Qinghai Lake as the study site to represent the alpine sandy land. Before and after the windy season, erosion (deposition) depth in the fitting curve was measured. Then, the coefficient, the intensity rates and other quantitative indicators of erosion (deposition) were used to optimize three sizes $(1 \mathrm{~m} \times 1 \mathrm{~m}, 1.5 \mathrm{~m} \times 1.5 \mathrm{~m}$, and $2 \mathrm{~m} \times 2 \mathrm{~m}$ ) of straw checkerboard on different parts of the windward area (the bottom, the middle and the top of the slope), thereby providing scientific guidance for the practical application of straw checkerboard barriers in alpine sandy lands.

\section{Materials and methods}

\section{Study site}

Concerning the degree of desertification, the sandy land along the eastern shore of the Qinghai Lake ranges from extremely severe to severe. The types of sand dunes are primarily barchans and transverse dunes. The elevation of the sandy land is $3,200 \mathrm{~m}$, and area is $753 \mathrm{~km}^{2}$. Moreover, the area is located at the intersection of the eastern monsoon region and the Qinghai-Tibet Plateau, and annual average temperature, precipitation and wind speed are $0.7^{\circ}$ $\mathrm{C}, 370 \mathrm{~mm}$ and $4 \mathrm{~m} \mathrm{~s}^{-1}$, respectively. In winter and spring, the prevailing westerly and northwesterly winds are influenced by the westerly winds, whereas the northeasterly and southwesterly winds are primary winds affected by the "lake effect" in summer and autumn. Furthermore, annual and daily wind variation in the region is larger.

The Ketu sandy area (Fig. 1) is located in the southeast corner of Haiyan Bay, blocked by the Riyue Mountains in the east. Mega-dunes and continuous mobile dunes are distributed in the eastern part of the district. Since the early 1980s, the government has taken measures to contain mobile dunes in the west district, and now a large area of shifting dunes has been contained. The most commonly used containment method was wheat straw checkerboards and afforestation for enclosure, eventually, promoting vegetation restoration. In 2008, during the "11th Five- 
Fig. 1 The map of study area

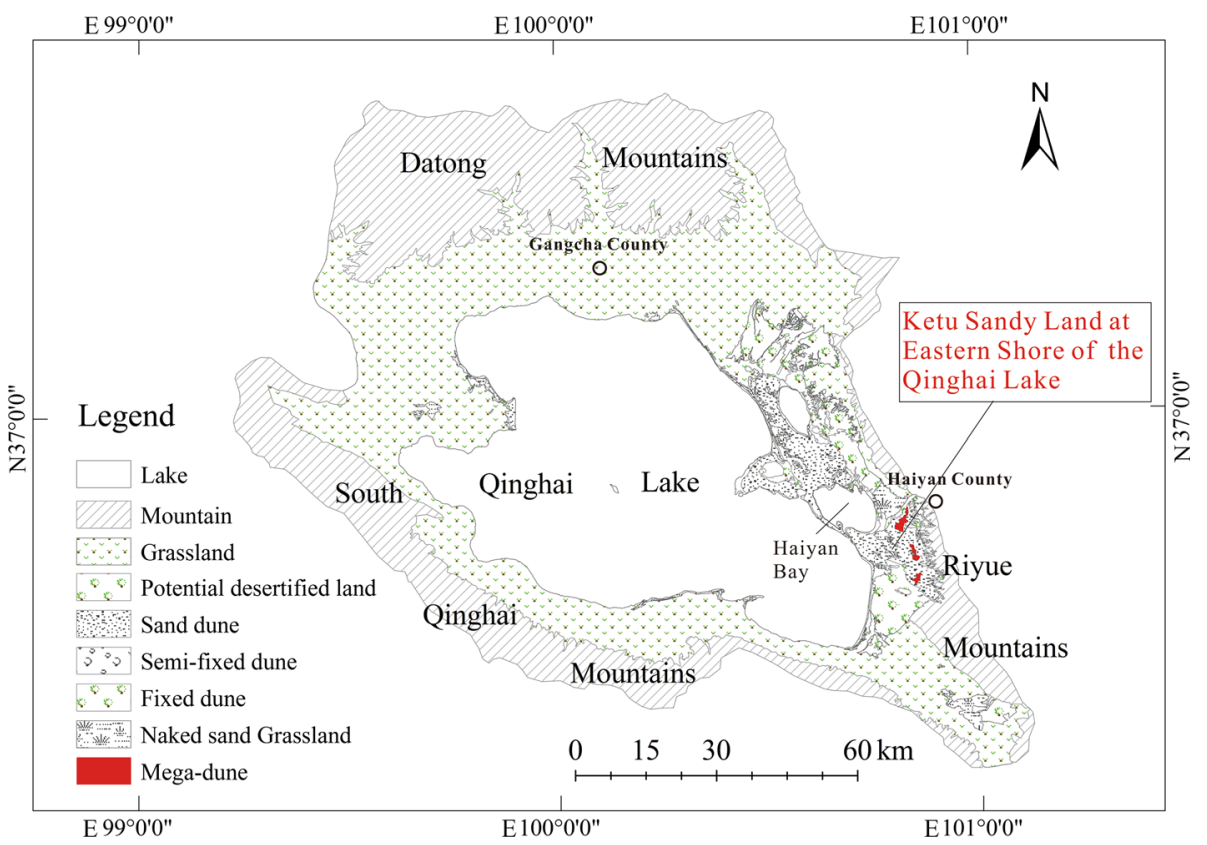

Year" plan, supported by the Ministry of Science and Technology of the People's Republic of China, Beijing Normal University enclosed an approximately $667 \mathrm{hm}^{2}$ test site to study sand prevention and technology integration. Through 2012, approximately $96 \mathrm{hm}^{2}$ of straw checkerboard barriers were established and $448 \mathrm{hm}^{2}$ were afforested. The wind speed is $6.5 \mathrm{~m} \mathrm{~s}^{-1}$ on mobile dunes and exceeds $8 \mathrm{~m} \mathrm{~s}^{-1}$ on treatment dunes, now. The average barrier height was approximately $15-20 \mathrm{~cm}$, providing effective protection for 3 years and playing a vital role as a windbreak and in sand fixation.

\section{Plot preparation}

Within the experimental district that was enclosed in 2008, a windward slope was chosen whose length was $250 \mathrm{~m}$ from north to south and was $35 \mathrm{~m}$ wide from east to west. The different sizes of wheat straw checkerboards were then devised in the summer of 2012. As shown in Fig. 2, the different sizes were divided into intervals of approximately 30-35 m (W-E width $\times \mathrm{N}-\mathrm{S}$ length). The zone was divided into 7 plots: $C$ plot $(1.5 \mathrm{~m} \times 1.5 \mathrm{~m}), E(1.5 \mathrm{~m} \times 2 \mathrm{~m})$, $F(2 \mathrm{~m} \times 2 \mathrm{~m}), D(1 \mathrm{~m} \times 2 \mathrm{~m}), B(1 \mathrm{~m} \times 1.5 \mathrm{~m}), A$ $(1 \mathrm{~m} \times 1 \mathrm{~m})$ and $M$ (mobile sand control plot) from north to south. Each plot measured approximately $900 \mathrm{~m}^{2}$ from west to east and was divided into three parts, where $X$ is the bottom of the windward area, $Y$ is the middle of the windward area, and $Z$ is the top of the windward area. In every part, three checkerboards were constructed because repetitions were necessary for the experiment. In the following study, only the typical square grid $A, C$ and $F$ are analyzed.
Fitting curve

Before the start of the windy season (August 22, 2012), the land was flattened inside of the checkerboard and the height of barriers was built to $15 \mathrm{~cm}$. Through the end of the season (April 1, 2013), the curve was measured using a combination of steel tape and tape (Dong and Wu 2010). According to the "米” glyph principle, four bearing lines were divided (W-E, N-S, NW-SE, NE-SW) and eight bearing areas were formed in the checkerboard (Fig. 3). In addition, approximately $2-5$ points were chosen at random in each bearing area, forming a dense point network of cell measurements. Then, timber piles were fixed around the checkerboard. The tape was tightened along the bearing line on two piles when measuring, ensuring that the height of the tape measure line and straw height were highly consistent with $15 \mathrm{~cm}$ of exposed steel tape as a reference, that is parallel to the original flat surface. Finally, the distance $(d)$ between the measuring point and heights of the $15 \mathrm{~cm}$ tape baseline was measured at $5 \mathrm{~cm}$ intervals along the bearing line using the steel tape. It is essential to measure the height of random measurement points using $d$.

Using the Matlab software for specialized equipment, the spline interpolation and three-dimensional fitting curve analyzed the measuring data to obtain the different depths of erosion (deposition) $h$ ( $h=15-\mathrm{d}, h>0$ for deposition, $h<0$ for erosion). Then, ArcGIS was used to calculate $S_{\mathrm{i}}$, the area of erosion (deposition) of different depths that accounts for the whole checkerboard. Finally, Excel was used to draw a transect curve of the erosion (deposition) along a NW-SE and NE-SW orientation in the fitting curve. 
Fig. 2 The map of different sizes of straw checkerboards in the Ketu sandy land

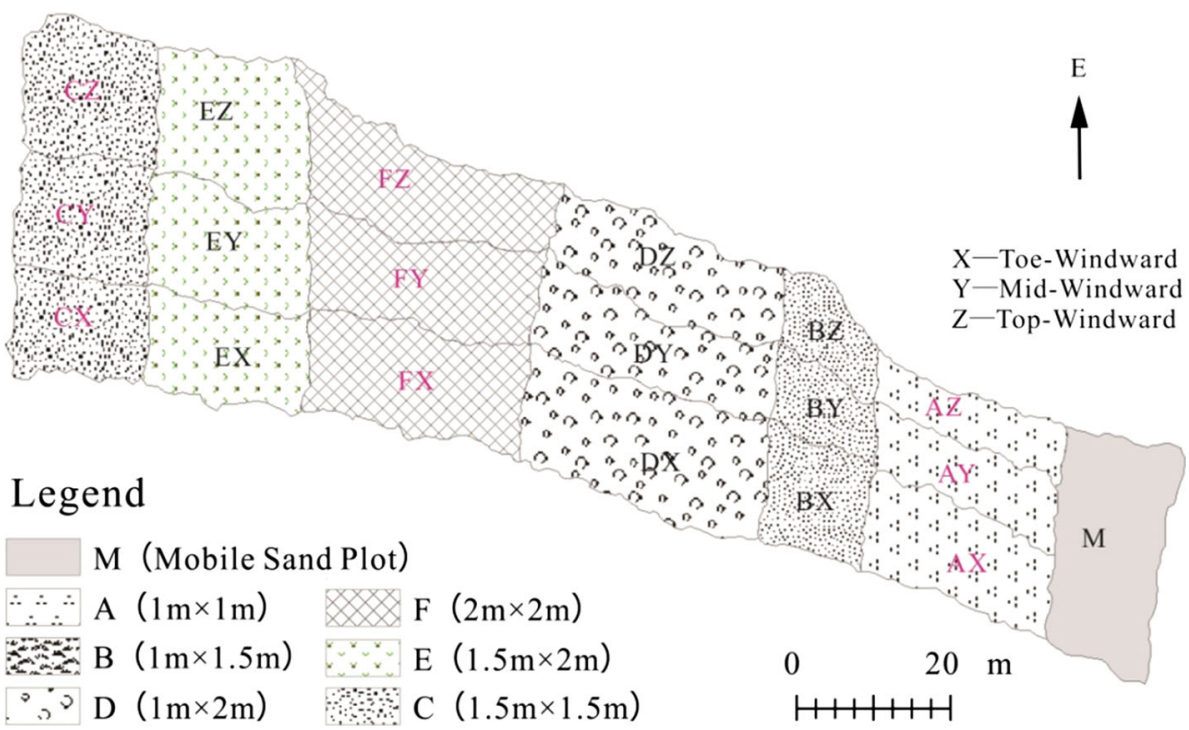

Fig. 3 Measuring the fitting curve

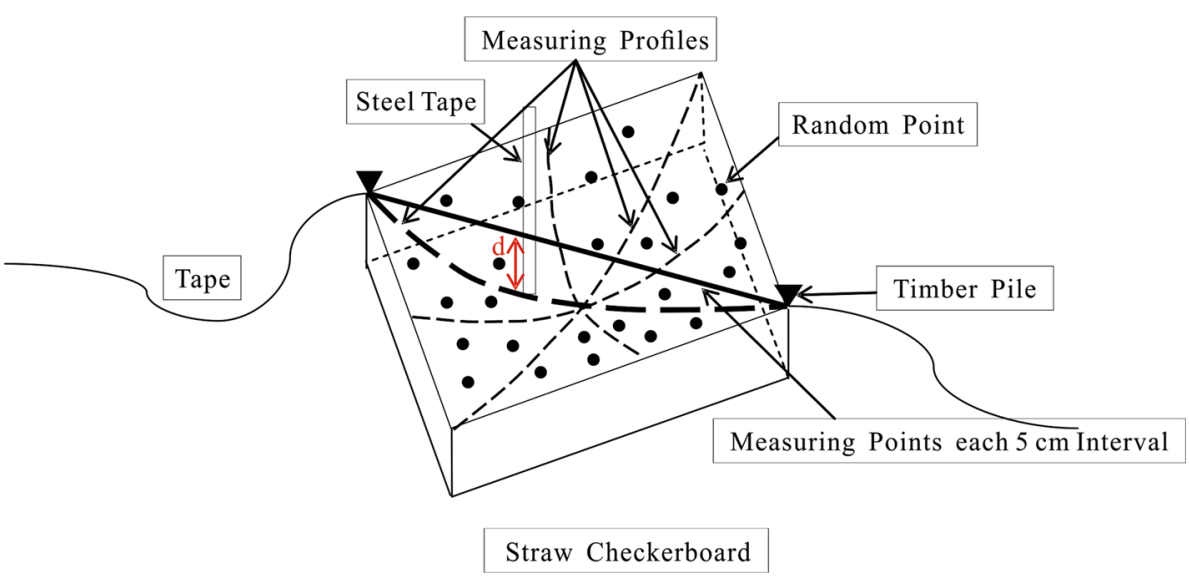

Statistics of the quantitative indicators

The erosion (deposition) coefficient $(R)$ is expressed in Eq. (1) as

$R=1 / H$,

where $R$ is the erosion (deposition) coefficient and $H$ is the depth of the center point $(\mathrm{cm}) . R$ is more likely to be 0.1 , which indicates that the concave surface is more stable.

The erosion (deposition) amount $(Q)$ is expressed in Eq. (2) as

$Q=q \times \sum\left(S_{\mathrm{i}} \times h_{\mathrm{i}}\right) / 1000$,

where $Q$ is the erosion (deposition) amount inside the straw checkerboard $(\mathrm{kg}), S_{\mathrm{i}}$ is the area of the erosion (deposition) at different depths that accounts for the whole checkerboard (\%), $h_{\mathrm{i}}$ is the average depth of erosion or deposition (cm), and $q$ is the density of topsoil $\left(\mathrm{g} \mathrm{cm}^{-3}\right)$.
The intensity of the erosion (deposition) $\left(Q_{\mathrm{m}}\right)$ is expressed in Eq. (3) as

$Q_{\mathrm{m}}=Q / S$

where $Q_{\mathrm{m}}$ is the intensity of the erosion (deposition) inside the straw checkerboard $\left(\mathrm{kg} \mathrm{m}^{-2}\right), Q$ is the sand erosion (deposition) amount inside the checkerboard $(\mathrm{kg})$, and $S$ is the area of the checkerboard $\left(\mathrm{m}^{2}\right)$. If $Q_{\mathrm{m}}$ is greater than 0 , then there is deposition, and if $Q_{\mathrm{m}}$ is less than 0 , then there is erosion.

The intensity of erosion (deposition) in the transect $\left(Q_{\mathrm{p}}\right)$ is expressed in Eq. (4) as

$Q_{\mathrm{p}}=\int_{0}^{d}\left(h_{i} \times q\right) \mathrm{d} t$,

where $Q_{\mathrm{p}}$ is the intensity of erosion (deposition) in the transect $\left(\mathrm{kg} \mathrm{m}^{-2}\right), d$ is the distance range from origin $(\mathrm{cm})$, $h_{\mathrm{i}}$ is the average depth of erosion (deposition) (cm), and $q$ 
is the density of topsoil $\left(\mathrm{g} \mathrm{cm}^{-3}\right)$. The significance of $Q_{\mathrm{p}}$ is same as $Q_{\mathrm{m}}$.

\section{Results and discussion}

Morphological characteristics of the fitting curve

On the basis of the fitting curve features, with the spline interpolation process, the various sizes of straw checkerboards indicate that the deposition depth is reduced from the margin to the center, whereas the center-east is the weak accumulation or erosion orientation. In addition, it is obvious that the erosion occurred on the diagonal, which is related to northwesterly and southwesterly prevailing winds and airflow aggregated on the diagonal. Nevertheless, with different sizes of checkerboards, significant differences exist in shape and depth at diffident morphologies. On the whole, for the main site, the depth range and erosion (deposition) area present overall in consistencies and local uniqueness (Fig. 4; Table 1).

For the same part of the windward area, the bigger the square of straw checkerboard $(A \rightarrow \mathrm{C} \rightarrow \mathrm{F})$, the deeper the depth, the bigger the range, the greater the erosion, and the weaker the deposition. Because of the unstable airflow inside the checkerboard, the erosion area is extended from the single direction to multiple directions $(A, C$ and $F$ ). The fitting curve that is simple erosion or deposition status under primarily wind direction gradually becomes more similar to valley basin and trenches micro-relief complex forms.

At the bottom of the windward area $(X)$, along with the square increases, multiple weak accumulations occurred in the southeast, northeast and southwest, and the depth ranges increased. Within approximately $10-15 \mathrm{~cm}$ in depth, the percent of the accumulation area decreased from 87.75 to $32.75 \%$, and at approximately $0-5 \mathrm{~cm}$ in depth, the area increased from 1.16 to $27.37 \%$. At that time, weak erosion appeared. Following the low accumulation area, the depth increased gradually, differences in the intensity of accumulation were increasingly more in the center and surroundings.

There is little change in the weak deposition bearings of the fitting curve at the middle of the windward area $(Y)$ in different sizes of straw checkerboards. At the accumulation of approximately $5-10 \mathrm{~cm}$ depth, $C$ is the largest deposition proportion, and the ratio of $F$ decreases approximately 30 and $15 \%$ compared with $A$ and $C$, respectively. Alternatively, the deposition rate of $\mathrm{F}$ noticeably decreased and appeared at approximately -10 to $0 \mathrm{~cm}$ of erosion. With the increase of the barrier spacing, the top of the windward slope $(Z)$ clearly indicates that the accumulation converted to erosion. The $A$ and $C$ square are given accumulation priority, but at a depth of approximately -5 to $0 \mathrm{~cm}$, the erosion ditch appeared in $C Z$, whereas $F$ encountered sheet erosion in the SE-NE orientation with a maximum depth of $14.55 \mathrm{~cm}$ and an erosion area ratio of $30.25 \%$.

For the same size, from the bottom to the top of the windward slope $(X \rightarrow Y \rightarrow Z)$, the depth range of the erosion (deposition) gradually increased. At the same time, the erosion becomes stronger, while the deposition becomes weaker. There is no clear change in a different site, but less-grand extensions exist in the checkerboard. For $1 \mathrm{~m}$ checkerboard intervals $(A)$, the different parts are mainly accumulation. From $X, Y$ to $Z$, the average deposition depth is reduced, but the strongest accumulation zone is on top. Compared to $A X$, the area of deposition depth of approximately $0-5 \mathrm{~cm}$ increased $21 \%$ in $A Z$, and the area of approximately $5-10 \mathrm{~cm}$ in depth increased $35 \%$. The weak accumulation area extends from southeast to northeast. Each part of the $1.5-\mathrm{m}$ distance between the straw checkerboards $(C)$ is given priority to the accumulation of approximately $5-15 \mathrm{~cm}$ in depth. The erosion gradually increases from $X, Y$ to $Z$. An erosion hole appeared at the southeast and southwest at depths of approximately 0 $5 \mathrm{~cm}$. When compared with $C X$ and $C Y$, there is approximately $50 \%$ in approximately $5-10 \mathrm{~cm}$ in depth accumulation. In the largest $2 \mathrm{~m}$ space size $(F)$, the area of erosion is bigger and the intensity of deposition decreases following $X, Y$ and $Z$, and the percent of the area in the erosion state is $2.75,25.43$ and $29.42 \%$, respectively. The top of the windward slope in the severe erosion state is approximately $15 \%$.

On the whole, $Z$ is susceptible to erosion and weaker deposition. At the site, the ratio of the deposition is greater than erosion, and the accumulation area is partial to the NE-SE orientation. Alternatively, the bottom of the windward slope $(X)$ is the greatest accumulation site, and the percent of the moderate and severe deposition intensity is greater than $70 \%$. East is the primary orientation that erosion and deposition happened at $Y$ and the depth of erosion (deposition) is between $X$ and $Z$.

Erosion (deposition) coefficient $(R)$, erosion (deposition) amount $(Q)$ and intensity of erosion (deposition) $\left(Q_{\mathrm{m}}\right)$

The advantages and disadvantages of each size of the straw checkerboard depend on whether the concave surface is stable. The coefficient of erosion and deposition $(R)$ is an important index evaluating the stability of the concave surface. According to Table 2, the values of $R$ in $A Z, C X$, $C Y$, and $C Z$ are between 0.09 and 0.1 , which reflects the stability of the concave surface. That $R$ in $A X$ and $A Y$ is less than 0.07 indicates the occurrence of a strong accumulation phenomenon that leads to the concave surface being close 

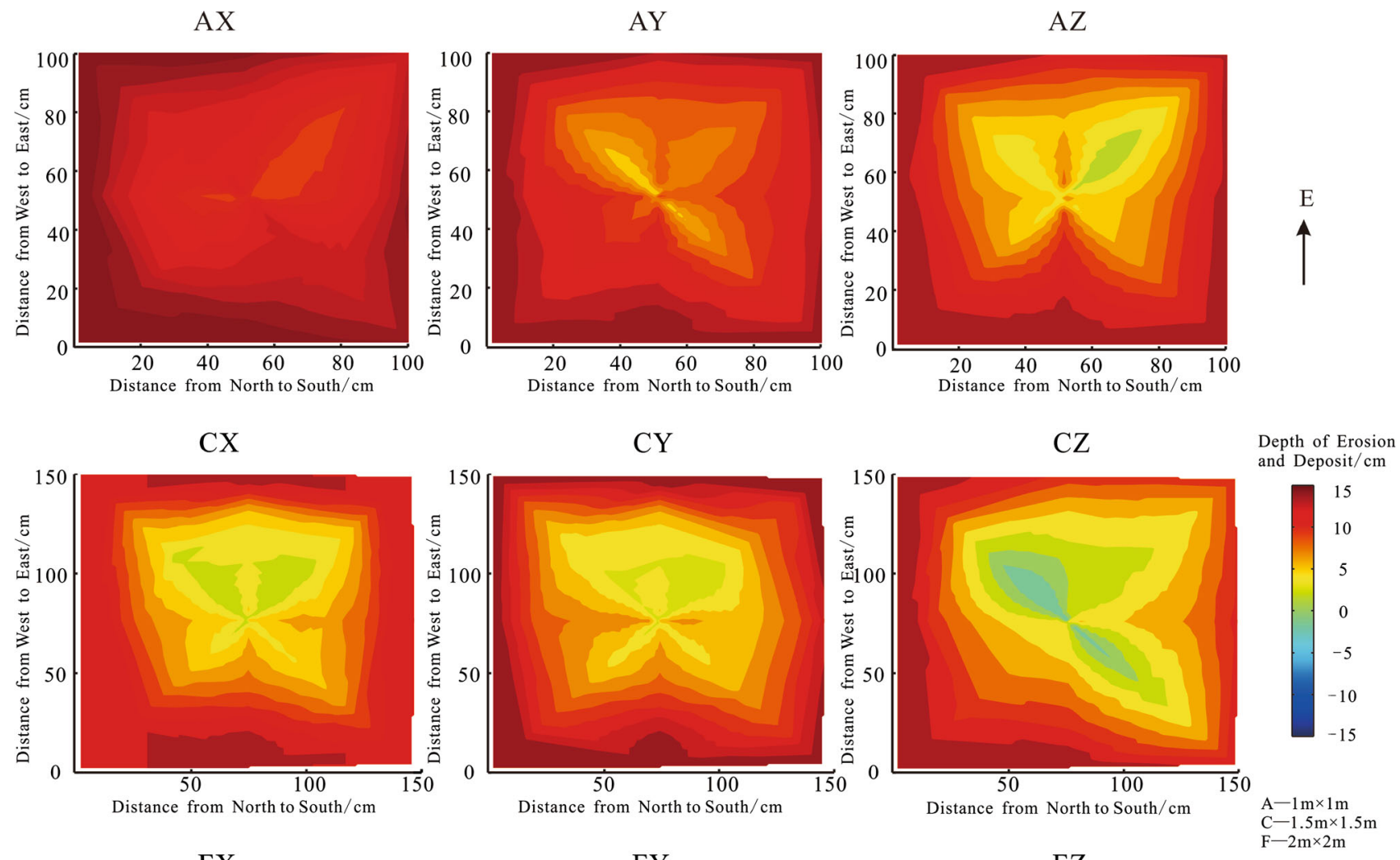

CZ

FX

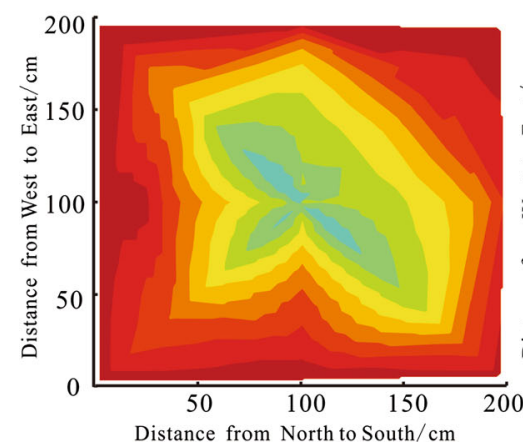

FY

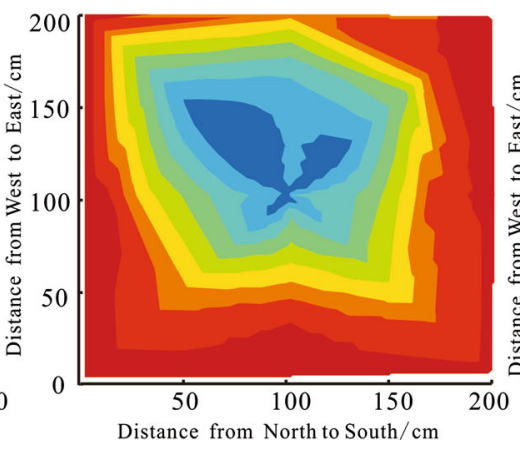

FZ

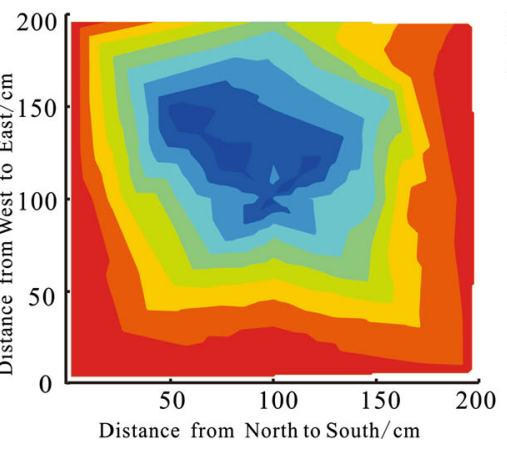

$\mathrm{X}$-Toe-Windward $Y$-Mid-Windward Z-Top-Windward

Fig. 4 Morphological characteristics of the fitting curve

Table 1 Percentages of different depths of erosion (deposition)

\begin{tabular}{lllllllll}
\hline Types of straw checkerboards & \multicolumn{7}{l}{ Percentages of different depths of erosion (deposition) $(\%)$} \\
\cline { 2 - 8 } & {$[-15,-10]$} & {$[-10,-5]$} & {$[-5,0]$} & {$[0,5]$} & {$[5,10]$} & {$[10,15]$} & {$[15,20]$} \\
\hline$A X$ & 0.00 & 0.00 & 0.00 & 1.16 & 11.09 & 87.75 & 0.00 \\
$A Y$ & 0.00 & 0.00 & 0.00 & 6.79 & 31.32 & 61.89 & 0.00 \\
$A Z$ & 0.00 & 0.00 & 0.00 & 22.80 & 46.31 & 28.64 & 2.25 \\
$C X$ & 0.00 & 0.00 & 0.00 & 14.79 & 43.23 & 41.90 & 0.08 \\
$C Y$ & 0.00 & 0.00 & 0.00 & 14.06 & 53.32 & 32.59 & 0.02 \\
$C Z$ & 0.00 & 0.00 & 2.15 & 24.61 & 48.37 & 24.87 & 0.01 \\
$F X$ & 0.00 & 0.00 & 2.75 & 27.37 & 37.13 & 32.75 & 0.00 \\
$F Y$ & 0.00 & 8.56 & 16.87 & 19.83 & 24.46 & 30.28 & 0.00 \\
$F Z$ & 0.83 & 13.05 & 16.37 & 19.81 & 25.75 & 24.20 & 0.00 \\
\hline
\end{tabular}


Table 2 Characteristics of the fitting curve in different sizes of straw checkerboard

\begin{tabular}{lllllll}
\hline $\begin{array}{l}\text { Types of straw } \\
\text { checkerboards }\end{array}$ & $\begin{array}{l}\text { Average } \\
\text { height }(\mathrm{cm})\end{array}$ & $\begin{array}{l}\text { Depth of center } \\
\text { point } \mathrm{H}(\mathrm{cm})\end{array}$ & $\begin{array}{l}\text { Erosion (deposition) } \\
\text { coefficient R }\end{array}$ & $\begin{array}{l}\text { Erosion } \\
\text { amount QE }(\mathrm{kg})\end{array}$ & $\begin{array}{l}\text { Deposition } \\
\text { amount } \mathrm{Q}_{\mathrm{D}}(\mathrm{kg})\end{array}$ & $\begin{array}{l}\text { Intensity of erosion } \\
(\mathrm{deposition})\end{array} \mathrm{Qm}_{\mathrm{kg} \mathrm{m}}{ }^{-2}$ \\
\hline$A X$ & 2.5 & 4.35 & 0.0435 & 0 & 120.63 & 120.63 \\
$A Y$ & 4.8 & 6.90 & 0.0690 & 0 & 107.52 & 107.52 \\
$A Z$ & 6.2 & 9.35 & 0.0935 & 0 & 92.34 & 92.34 \\
$C X$ & 7.2 & 12.80 & 0.0853 & 0 & 195.58 & 86.92 \\
$C Y$ & 7.6 & 13.60 & 0.0910 & 0 & 188.56 & 83.81 \\
$C Z$ & 9.3 & 16.90 & 0.1127 & 0.27 & 153.62 & 68.15 \\
$F X$ & 8.8 & 18.40 & 0.0920 & 6.74 & 292.70 & 72.99 \\
$F Y$ & 9.6 & 23.40 & 0.1170 & 37.15 & 229.54 & 48.10 \\
$F Z$ & 11.5 & 26.70 & 0.1335 & 58.77 & 216.74 & 54.19
\end{tabular}

to flat without any type of wind erosion groove. Strong erosion occurred in the center of $F Y$ and $F Z$ because $R$ is greater than 0.1 . Finally, the pits and sand ditch distribute in the concave surface.

The erosion (deposition) amount can quantitatively reflect the internal physical changes in the square. From the values of the erosion (deposition) amount in Table 2 , in the bigger square $(A, C$ to $F)$, the greatest differences in accumulation amount are generated at the different sites. Normally, the erosion (deposition) amount in $X$ is greater than $Y$ and $Z$. The evidence shows that an erosion phenomenon did not occur in $A, B$ only has weak erosion at the top, and $C$ has strong erosion in each part along the slope. In addition, the erosion amount in $C Z$ is approximately 8.7 times that of $X$ and 1.6 times that of $Y$.

The magnitude of erosion (deposition) $\left(Q_{\mathrm{m}}\right)$ is weaker along with the square increases $(A \rightarrow C \rightarrow F)$ and the site from $X, Y$ to $Z$. In this process, the accumulation intensity is greater than the erosion. On the same site, the $Q_{\mathrm{m}}$ of $A$ is approximately 1.3-1.4 times that of $C$, and approximately 1.7-2.2 times that of $\mathrm{F}$. In the same square, the $Q_{\mathrm{m}}$ of $X$ is approximately 1.04-1.52 times that of the $Y$ and approximately 1.31-1.37 times that of $Z$. In all, at the bottom of the slope, the small size of the straw checkerboard is under severe deposition, whereas the large square is erosion at the top of the windward slope. After a windy season, the average height of the $A$ barrier is less than $6 \mathrm{~cm}$, whereas the sand barrier occurred at the bottom. However, the height of the barrier of $C$ makes the balance from 7 to $10 \mathrm{~cm}$, the average height of the $F$ barrier exceeds $9 \mathrm{~cm}$ and the wheat straw is under severe erosion.

Erosion (deposition) curve in the transect

The erosion (deposition) curve in the NW-SE and NE-SW orientation (Fig. 5) is similar in the same site at the same square and transect; however, the depth and intensity have a large difference (Table 3).
On the transect of the NW-SE orientation, at the dune section, each square in the NW orientation is the strong accumulation zone and the center-SE azimuth is the weak deposition and erosion area. Along the windward slope from $X, Y$ to $Z$, the average accumulation depth in the northwest orientation is $9.56,8.57$ and 7.48 , respectively, whereas the average depth of the deposition in the center-SE orientation is, respectively, 8.28, 5.67 and 3.10. Overall, the average intensity of the erosion (deposition) in the transect is 0.85 , 0.70 and $0.52 \mathrm{~kg} \mathrm{~m}^{-2}$, respectively. For the different sizes of the same part, the northwest orientation is the main accumulation zone within the performance outline. The average depth and intensity of erosion or deposition in the largesized straw checkerboard is less than the small and middlesized checkerboard. However, the strongest intensity of erosion is in the center-southeast orientation.

The depth of erosion (deposition) in different sizes of $A$, $C$ and $F$ in the northwest orientation is $11.09,9.01$ and 5.50 , respectively, and $8.96,6.15$ and 1.94 on the southeast orientation. The integral average intensity of erosion (deposition) in the transect is $0.98,0.69$ and $0.38 \mathrm{~kg} \mathrm{~m}^{-2}$, respectively. Therefore, on one hand, the deposition of the northwest orientation shows that $X>Y>Z$, but $C Y$ is an exception, and $A>C>F$. On the other hand, the weak accumulation and erosion are ranked as $X<Y<Z$ and $A<C<F$. For $A$, it is the strong accumulation that is in the northwest and southeast orientation. In all, the erosion is stronger than the accumulation at the top of the windward slope of $F$.

In the NE-SW orientation, the primary accumulation place converted the southwest and center-northeast orientation to be the weak accumulation and erosion area. The primary accumulation place is similar in depth and intensity to the different sizes and sites on the NW-SE transect. Along the bottom, middle and top of the slope, the average deposition depth in the northeast orientation is 7.63, 4.46 and 2.65 , respectively. The average depth of the deposition in the southwest orientation is 9.01, 8.51 and 7.34, whereas 

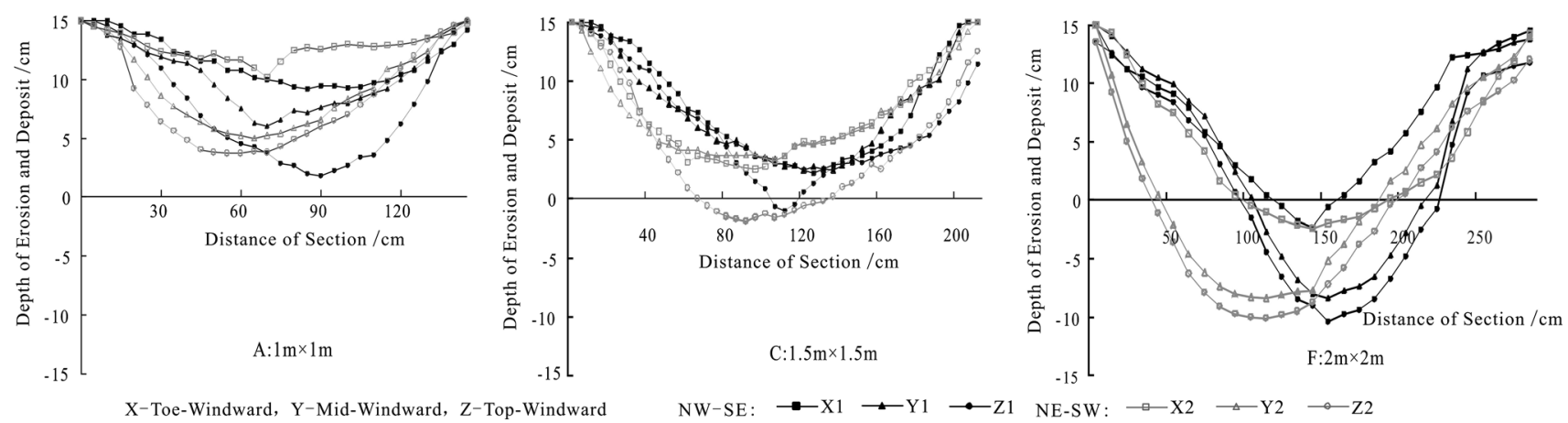

Fig. 5 Erosion (deposition) curves in the NW-SE and NE-SW orientation in different sizes of straw checkerboards

Table 3 Intensity of erosion (deposition) on the transect $\left(Q_{\mathrm{p}}\right)$ in different sizes of straw checkerboards

\begin{tabular}{|c|c|c|c|c|c|c|}
\hline \multirow{2}{*}{$\begin{array}{l}\text { Types of } \\
\text { straw } \\
\text { checkerboards }\end{array}$} & \multicolumn{3}{|l|}{ NW-SE } & \multicolumn{3}{|l|}{ NE-SW } \\
\hline & $\begin{array}{l}\text { Average depth of } \\
\text { erosion (deposition) } \\
\text { in Northwest } \\
\text { orientation }(\mathrm{cm})\end{array}$ & $\begin{array}{l}\text { Average depth of } \\
\text { erosion (deposition) } \\
\text { in Southeast } \\
\text { orientation }(\mathrm{cm})\end{array}$ & $\begin{array}{l}\text { Intensity of } \\
\text { erosion } \\
\text { (deposition) in } \\
\text { transect Qp } \\
\left(\mathrm{kg} \mathrm{m}^{-2}\right)\end{array}$ & $\begin{array}{l}\text { Average depth of } \\
\text { erosion (deposition) } \\
\text { in Northeast } \\
\text { orientation, } \mathrm{cm}\end{array}$ & $\begin{array}{l}\text { Average depth of } \\
\text { erosion (deposition) } \\
\text { in Southwest } \\
\text { orientation, cm }\end{array}$ & $\begin{array}{l}\text { Intensity of } \\
\text { erosion } \\
\text { (deposition) in } \\
\text { transect Qp } \\
\left(\mathrm{kg} \cdot \mathrm{m}^{-2}\right)\end{array}$ \\
\hline$A X$ & 12.69 & 10.68 & 1.14 & 12.61 & 12.88 & 1.27 \\
\hline$A Y$ & 11.05 & 9.59 & 1.03 & 9.28 & 9.56 & 0.93 \\
\hline$A Z$ & 9.53 & 6.61 & 0.76 & 8.11 & 10.09 & 0.83 \\
\hline$C X$ & 9.63 & 7.69 & 0.76 & 6.83 & 8.24 & 0.70 \\
\hline$C Y$ & 8.76 & 6.77 & 0.74 & 6.37 & 7.89 & 0.68 \\
\hline$C Z$ & 8.64 & 3.99 & 0.58 & 3.66 & 5.14 & 0.34 \\
\hline$F X$ & 6.37 & 6.48 & 0.64 & 3.46 & 5.90 & 0.38 \\
\hline$F Y$ & 5.87 & 0.66 & 0.32 & -2.27 & 8.07 & 0.08 \\
\hline$F Z$ & 4.26 & -1.31 & 0.16 & -3.81 & 6.79 & -0.10 \\
\hline
\end{tabular}

the accumulation on the southwest is stronger than the northeast $(P>0.01)$, and the integral average intensity of erosion (deposition) in the transect is $0.79,0.56$ and $0.37 \mathrm{~kg} \mathrm{~m}^{-2}$. In total, the accumulation effect of the bottom is stronger than the top $(P>0.01)$.

At the same landscape, for $A, C$ and $F$, the average depth of the deposition in the northeast orientation is $10.10,5.62$, and $-0.87 \mathrm{~cm}$, respectively, and $10.84,7.09,6.92 \mathrm{~cm}$, respectively, in the southwest. The accumulation effect in the northeast is similar to the southwest orientation in $A$. And for $F$, the erosion occurred in the northeast orientation, whereas the southwest was mainly dominated by deposition $(P>0.01)$. Considering the intensity of the erosion or deposition, the intensity of the large size is approximately $0.1-0.6$ times that of the small size and 0.3-0.8 times that of the medium size. On the whole, the erosion is obvious.

Effects of windbreak and sand fixation

Different sizes of straw checkerboards at different sites reflect the ability to resist wind erosion and sand burial, which can be expressed by the windbreak function $P$ within a $2 \mathrm{~m}$ height that is the wind reduction percentage compared with the same height of sandy land with no barriers. According to a field experiment in 2013, at the bottom $(X)$ and middle $(Y)$ of the windward slope, the $P$ value is similar for $A$ and $C$, whereas at the top (Z), $A$ is $10 \%$ larger than $C$. Comparing $C$ with $F$, the $P$ value in $X, Y$ and $Z$ is bigger, which is approximately 1.8-2.5 times that of the latter (Fig. 6).

The sand-fixation efficiency $S$ is the sediment discharge reduction percentage compared to sandy land without a barrier height, presented as $A>C>F$ at the middle site of the windward slope. The ratio of the $S$ value is approximately 20:19:17, and the ratio of the differences at the site is characterized by $X<Y<Z$. The $P$ and $S$ near the ground in $F$ is less than the $A$ and $C$ at the $Z$ site, and the windward side is vulnerable to erosion, which is easily destroyed. At the same time, this site is prone to generating a secondary vortices cyclotron and, finally, to expanding in the erosion area of the checkerboard. After excessive sand burial at the bottom and middle part of the windward slope, the 

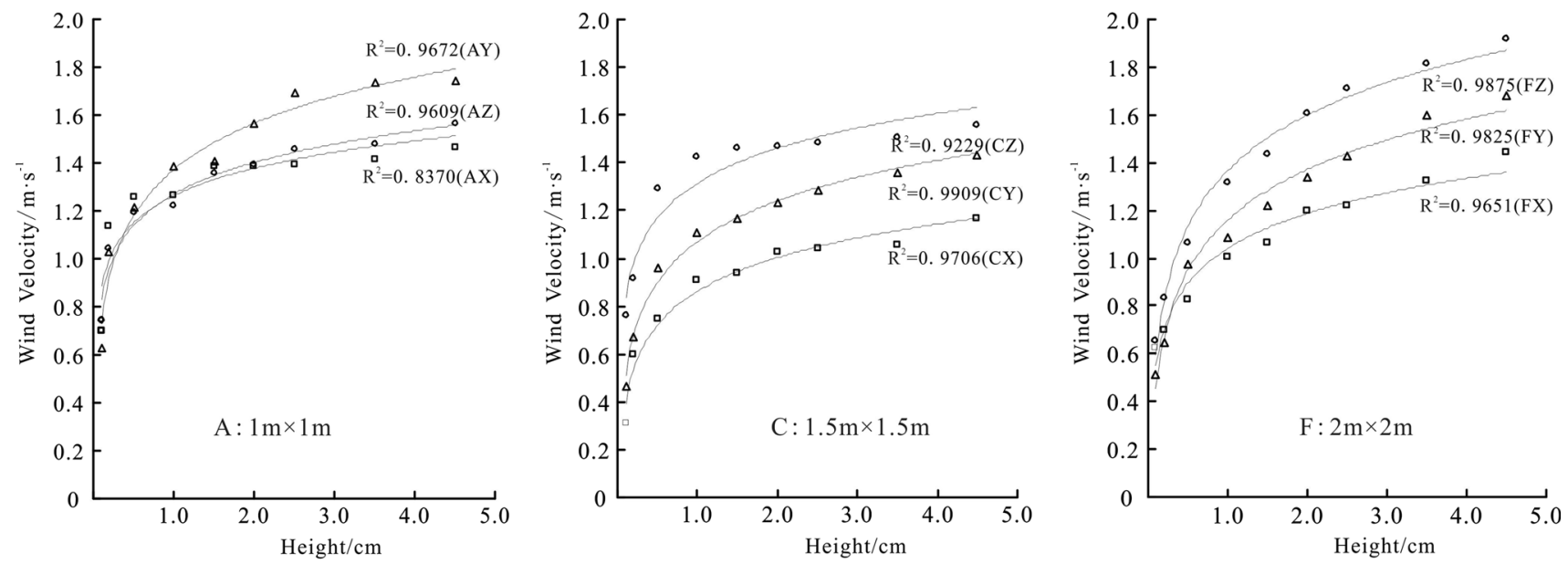

口 $\mathrm{X}$ (Toe-Windward) $\Delta \mathrm{Y}($ Mid-Windward) $\diamond \mathrm{Z}$ (Top-Windward) $\longrightarrow$ Logarithmic Curve

Fig. 6 Wind velocity profiles of different sizes of straw checkerboards

windbreak and sand-fixation effect of $A$ will gradually decline. Finally, less than in a windy season, $A$ will be buried. Because $\mathrm{C}$ has a relatively stable erosion and deposition fitting curve, and the protection effect is moderate between $A$ and $F$, the maximum duration of protection is the longest.

Relationship between the characteristics of erosion (deposition) and wind velocity and frequency

Wind velocity and direction are the primary factors that affect the differences in erosion or deposition at the site in the fitting curve. Based on the meteorological data, during the observation period, the dominant wind directions are southwest and northwest. The wind frequency is 25.75 and $40.05 \%$ and the average wind velocity is 4.46 and $5.82 \mathrm{~m} \mathrm{~s}^{-1}$, respectively. In combination with the depth of the four obtained consecutive insert bit measurements, each part of the exposed steel changed during the period, i.e., the depth of the erosion or deposition in the different periods changed, and the wind data changed in the corresponding time. During the different stages, the frequency and average wind velocity in the southwest is related to the depth of accumulation on the southwest orientation, and the positive correlation coefficient is approximately $0.85-0.88$ and $0.87-0.85$, respectively. Furthermore, the positive correlation coefficient is approximately 0.89-0.92 和 and 0.900.93 , respectively, in the northwest, and the large size is affected by the wind velocity, and the frequency is superior to the small size. In addition, the center depth of the fitting curve is dominated by the season's wind frequency and velocity. Notably, this site is not at the minimum depth of the fitting curve but in the northeast bottom and northeast middle and top of the windward slope. The erosion pit is easily formed at the middle and top of the windward slope in the large size and at the top of the medium size, whereas in the middle and top of the slope, the small size is prone to being gradually affected by the shallow slot (Fig. 7).

\section{Application of different sizes of straw checkerboards}

When choosing the appropriate size of wheat straw checkerboards, the purpose of sand prevention needs to be considered and, in particular, the field conditions in alpine sandy land. In other words, measurements need to be adjusted according to local conditions. Furthermore, different sand dune areas need to establish different sizes. This has guiding meaning to promote the configuration of the sizes of checkerboards under different vegetation coverage, the intensity of wind and sand activity as well as some special purposes of sand dunes. The small size is useful to block sand at the top of the windward slope. The windward side of mega-dunes is affected by a strong flow, sand activities and an isolated protective belt, such as along

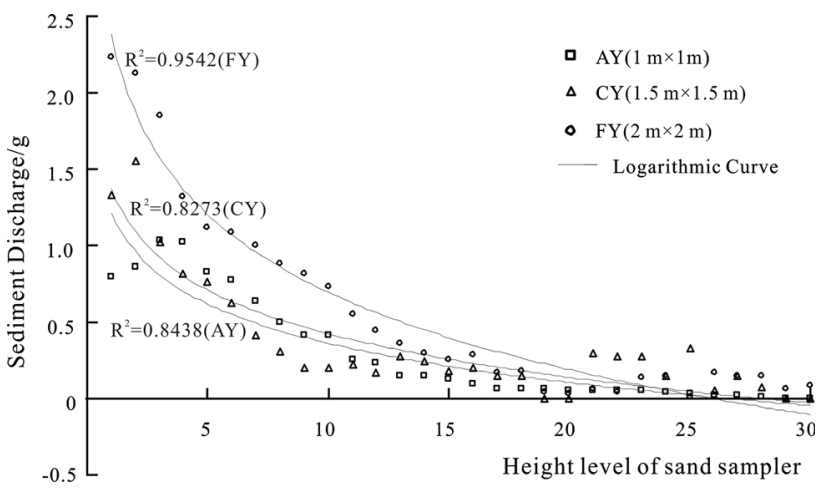

Fig. 7 Relationship between the sediment discharge and height in different sizes of straw checkerboards 
highways and railways. The role of the short-term emergency is the best for preventing the burial of railways and highways by sand. For the fixed, semi-fixed or mobile dunes' windward slope, vegetation is relatively good at preventing erosion or dune activation. The large size is enough to achieve the lowest economic cost and sand protection effect. If only to improve the survival rate of artificial vegetation or vegetation barriers before and after transplantation, the 1.5 and $2 \mathrm{~m}$ intervals were an economical and effective choice. The measures can reduce wind erosion and the sand buried, promote water accumulation infiltration and natural vegetation restoration, as well as extend protection under the vegetative protection to achieve a win-win situation. Therefore, the measures are widely applied in alpine sandy land promotion. In addition, considering the economic savings and practical simplicity, the rectangular and determinant barriers have practical applications. In areas where the dominant wind direction does not change or two nearly vertical winds dominate, the long side of rectangular barriers is vertical to the dominant wind direction. The trend of determinant barriers being vertical to dominant wind directions can also be widely used in alpine sandy land.

\section{Conclusions}

Different sizes of straw checkerboards at different parts of windward slopes have different stabilities and intensities of erosion (deposition) inside a fitting curve. The erosion (deposition) coefficient of an area $1 \mathrm{~m} \times 1 \mathrm{~m}$ is less than 0.07 , and the intensity of accumulation is greater than $100 \mathrm{~kg} \mathrm{~m}^{-2}$, leading to severe sand burial at the bottom and middle of a windward slope. The erosion (deposition) coefficient of an area $2 \mathrm{~m} \times 2 \mathrm{~m}$ is greater than 0.12 , and the magnitude of deposition is less than $50 \mathrm{~kg} \mathrm{~m}^{-2}$ at the middle and top of a windward slope. Finally, the centereast orientation in severe erosion and the basal sapping occurred on the windward slope of the checkerboard strongly erodes the basement of the wheat straw structure. For the $1.5 \mathrm{~m} \times 1.5 \mathrm{~m}$ square, the erosion (deposition) coefficient is approximately 0.1 , and the intensity of accumulation is stable at approximately $70 \mathrm{~kg} \mathrm{~m}^{-2}$ at the middle and top of the windward slope, which is the easiest to form stable concave surfaces and the minimum height of the barrier.

The transects of erosion (deposition) dominated by the southwesterly and northwesterly winds reflect the different intensities of erosion (deposition) at various orientations. Overall, the deposition effect in the northwest and southwest of the bottom-windward slope is greater than the middle-windward and top-windward, and the $1 \mathrm{~m} \times 1 \mathrm{~m}$ size is greater than the $1.5 \mathrm{~m} \times 1.5 \mathrm{~m}$ and $2 \mathrm{~m} \times 2 \mathrm{~m}$ size.
Conversely, the large size and top-windward slope is the best combination at the southeast and northeast orientation.

Different sizes of straw checkerboards are needed at different parts of the windward slope in alpine sandy land. The $1 \mathrm{~m} \times 1 \mathrm{~m}$ size is the most suitable one for windy topwindward slopes and the steepest mid-windward slopes, whereas the $2 \mathrm{~m} \times 2 \mathrm{~m}$ size is a more appropriate application for the bottom-windward slope and the gentle middle-windward slope than the $1 \mathrm{~m} \times 1 \mathrm{~m}$ size. Because the $1.5 \mathrm{~m} \times 1.5 \mathrm{~m}$ size has the most stable concave surface, moderate wind-prevention, sand-fixation benefit and affordable price, its application is feasible at each part of the slope.

Acknowledgments Supported by National Key Technology R\&D Program of China (No: 2012BAD16B0105), National Natural Science Foundation of China (No: 41171159), Provincial Natural Science Foundation of Qinghai, China (No: 2014-ZJ-902) and National Natural Science Foundation of China (No: 41461002).

\section{References}

An ZS, Zhang KC, Tan LH (2011) Process of aeolian sand erosion and sand controlling effect of fences with different height. Bull Soil Water Conversat 31(6):37-41

Bofah KK, Alhinai KG (1986) Field tests of porous fence in the regime of sand land wind. J Wind Eng Ind Aerodyn 23:309-319

Chang ZF, Zhong SN, Han FG (2000) Research of the suitable row spacing on clay barriers and straw barriers. J Desert Res 20 (4):455-457

Chen KZ, Huang DF, Liang DG (1964) The formation and development of Qinghai Lake. Acta Geogr Sin 3:214-233

Chepil WS, Woodruff NP (1963) The Physics of wind erosion and its control. Adv Agron 15:211-302

Ci LJ (1998) Mechanism of desertification and sustainable strategies to combat desertification in China. Quat Sci 2:97-107

Daniel RP, Ian JW, Giles FSW (2004) Numerical modeling of flow structures over idealized transverse aeolian dunes of varying geometry. Geomorphology 59:149-164

Ding LG, Yan P, Du JH (2009) Monitoring the state of erosion and deposition in straw checkerboard barriers based on 3D laser scanning technique. Sci Survey Map 34(2):90-92

Dong YX, Liu YH (1993) Review on the study of sandy desertification and its prospect. Geogr Res 12(2):94-102

Dong YF, Wu YQ (2010) Short-term gully erosion at different places of bottom of gully using virtual erosion pins. Sci Geogr Sin 30 (6):892-897

Dong GR, Gao SY, Jin J (1993) Sand desertification and its control in Gonghe basin. Sciences Press, Beijing, pp 1-226

Dong Z, Li HL, Hu CY (2006) Research on cost comparison and wind-break and sand-fixing benefits of different sand-fixing measures of highway in desert regions. Res Soil Water Conserv 13(2):128-130

Dong ZB, Luo WY, Qian GQ (2007) A wind tunnel simulation of the mean velocity fields behind upright porous fences. Agric For Meteorol 146:82-93

Fang HY, Cai GQ, Chen H (2007) Mechanism of formation of physical soil crust in desert soils treated with straw checkerboards. Soil Tillage Res 93:222-230

Fluent Inc (1998) Manual of computational fluid dynamics (CFD), Version 4.5. Fluent Inc., Lebanon, NH, USA 
Han ZW, Liu XW, Yao ZY (2000) Wind tunnel test on sandpreventing mechanism of double-filmed sand-bag obstacle and upright checkerboard sand-barrier. J Des Res 1:40-44

He DN, Zhao HB, Zhang DS (1993) On the characteristics of the sand-land and tendency of aeolian sandification in Qinghai Lake Basin. Sci Geogr Sin 13(4):382-388

Huang N, Xia XP, Tong D (2013) Numerical simulation of wind sand movement in straw checkerboard barriers. Eur Phys J 36:99-106

Iversen JD, Rasmussen KR (1999) The effect of winds Peed and bed slope on sand transport. Sedimentology 46:723-731

Li ZS (1999) Wind tunnel simulation of flow velocity on the windward slope. Res Soil Water Conserv 6(4):75-79

Li SY, Lei JQ (2003) The ecological restoration functions of the strawchecker sand- barriers: a case study along the desert highways in the Gurbantonggut Desert. Arid Zone Res 20(1):7-10

Li XR, Zhao HL, He MZ (2006) Sand barriers of straw checkerboards for habitat restoration in extremely arid desert regions. Ecol Eng 28:149-157

Liu LY (1999) The quantity and intensity of regional aeolian sand erosion and deposition: The case as Shanxi-Shanxi-Neimongol region. Acta Geogr Sin 54(1):59-68

Liu XW, Lin YQ, He DL (1983) Study on the experiment of the under-leading fence in wind tunnel-experiment under topographic conditions. J Desert Res 3:75-79

Liu LY, Song Y, Li XY (2006) Wind tunnel experiments on the deflation rates of different sediments in arid regions of China. Acta Geogr Sin 9:957-964

Ma QL, Wang JH, Zhan KJ (2005) Study on fixing sand principals of plastic checkerboard sand-barrier and its potential application. $\mathrm{J}$ Soil Water Conserv 19(1):36-39

Niu YF (1999) The study of environment in the Plateau of Qin-Tibet. Progress Geogr 18(2):1-9

Qian ZY (1986) Investigation on the sand harm to Qinghai-Xizang railway in yanqiao area and sand control plan. J Des Res 6 (2): $27-30$

Qiu GY, Lee I, Shimizu H (2004) Principles of sand dune fixation with straw-checkerboard technology and its effects on the environment. J Arid Environ 56:449-464

Qu JJ, Ling YQ, Zu RP (2005) Study on comprehensive sandprotecting efficiency of semi-buried checkerboard sand-barriers. J Des Res 3:329-335
Sun XK, Guo ZZ (1999) Study on principals of fixing sand with sand control hedge. J Gansu For Sci Technol 24(2):7-12

Sun T, Liu HJ, Zhu GQ (2012) Timeliness of reducing wind and stabilizing sand functions of three mechanical sand barriers in arid region. J Soil Water Conserv 26(4):12-22

Wang XH, Shen YC (2001) Farmland desertification and its control in the Qaidam Basin. J Des Res 21:43-47

Wang XQ, Zhao CJ (2002) Sand surface change and natural species entrance in straw barrier system in Gurbantonggute Desert, Xinjiang, China. Arid Land Geography 25(3):202-207

Wang ZT, Zheng XJ (2002) A simple model for calculating measurements of straw checkerboard barriers. J Des Res 22 (2):229-232

Wang XQ, Lu Q, Yang HH (2009) Field measurements of sandbarrier benefits and ecological functions in sandy lands of Qinghai-Tibet Plateau. J Soil Water Conserv 23(3):38-41

Wu Z (2009) Deserts in China and their management over the last 50 years. Arid Zone Res 26(1):1-7

Xu JL, Pei ZQ, Wang RH (1982) A Research on the width of the belt of half-hidden straw checkerboard barriers. J Des Res 2(3):16-22

Yang HW, Zhang DS, Zhang YX (1997) Land desertification in Qinghai high cold region and its control. J Des Res 17(2):185188

Zhang YX (2009) Study on quick control technique of migratory dune in Gonghe basin of Qinghai. J Qinghai Univ (Nat Sci) 27:56-64

Zhang DS, Gao SY (2007) Research progress on sand desertification in Qinghai Plateau. J Des Res 27(5):367-372

Zhang KC, Qu JJ, Dong ZB (2006) Preliminary research on fluctuation characteristics of wind speed over checkerboard sand barriers. Arid Zone Research 23(1):93-97

Zhang DS, Shi H, Wei DS (2011a) Characteristics of the sand flow structure of artificially governed sand dune on the east shore of Qinghai Lake. Scientia Silvae Sinicae 31(4):828-834

Zhang YH, Xu CJ, Qi Q (2011b) Climate change and ecological effect on the Tibetan plateau. J Qinghai Univ (Nat Sci) 29(4):1822

Zhou DD, Yu Y, Hu SR (2009) Concave surface characteristics of sandbag sand barrier. Bull Soil Water Conserv 29(4):22-25 